\title{
Tooth Shape Optimization of the NGW31 Planetary Gear Based on Romax Designer
}

\author{
Chunming $\mathrm{Xu}^{1, \mathrm{a}^{*}}$, Ze Liu ${ }^{1, \mathrm{~b}}$, Wenjun Chang ${ }^{1, \mathrm{c}}$ and Bei $\mathrm{Li}^{1, \mathrm{~d}}$ \\ ${ }^{1}$ College of Machinery and Automation, Wuhan University of Science and Technology, \\ 430081 Wuhan, China \\ a342430046@qq.com, b252772779@qq.com, 'c1519738162@qq.com, d1198413210@qq.com
}

Keywords: Romax Designer; Planet gear transmission; Tooth profile modification; Tooth lead modification; Optimization design.

\begin{abstract}
In order to reach the purpose of improving the gear's bearing capacity and the quality of transmission. With the NGW31 planetary gear as the research object, by using Romax Designer gear transmission simulation software, the gear original data and the surface contact stress distribution of sun gear and planet gear of the NGW31 planetary gear has been analyzed before gear modification. On this basis, the sun gear and planet gear of the NGW31 planetary gear has been modified. Comparing with the tooth surface contact stress distribution of the sun and planets gear of NGW31 planetary gear to modify front and back, it can be found that sun and planet gear tooth surface contact stress after modification shape is significantly lower than that of before the shape modification, which shows that the gear bearing capacity after modification shape has been improved obviously. The shock is decreased when the gear come into meshing and exited the meshing, the stability of transmission has been improved, achieving the purpose of optimizing to the NGW31 planetary gear.
\end{abstract}

\section{Introduction}

At present, the involute gear in the direction of development is "three high and one low", namely high bearing, high speed, high efficiency and low noise. How to improve the quality of transmission gear has become the key technology to realize "three high and one low". In addition to the conventional method of reducing the manufacturing and assembly errors of the gear to improve the transmission quality, at present, the gear tooth profile modification method is the most widely used method. From the beginning of the 1950s, scholars from all over the world have been working on gear tooth shape theory and method which were in-depth research, and put forward their modification method and the detailed experimental analysis, now in the engineering practice has been widely used and achieved remarkable effect[1-2]. In a pair of gear teeth in the meshing process, the deformation force will produce a certain amount of gear, two gear pitch is no longer equal, At this point the two gear will not be in the correct meshing, which produces a certain angular acceleration, increase the dynamic load, causing the vibration and shock of the gear, which is one of the main factors of noise generation [3]. In order to decrease the impact caused by the load deformation and base pitch error in tooth meshing process, to improve the lubrication conditions and to avoid tooth face scuffing occurs. Therefore, removing the certain materials from tooth profile of the theory on the tooth top position or near the fillet position to profile modification [4-5]. At the same time, in the meshing process, due to the factors as the influence of teeth to the error, elastic deformation of gear and shaft, bearing clearance, the bearing hole deformation, the uneven distribution of the load along the direction of the tooth width is caused. In extreme cases, the local concentration of the load will cause tooth surface damage, therefore, modifying the tooth surface along the tooth width direction to carry out the tooth profile modification, the condition of uneven load distribution can be improved by the tooth profile modification [6].Tooth profile modification and tooth profile modification are the two main methods of gear tooth modification. In this paper, the NGW31 type planetary gear as the research object, Gear tooth modification and optimization are carried out by Designer Romax gear transmission simulation 
design software, in order to improve the contact stress distribution of tooth surface, improve the bearing capacity of the gear and the transmission quality of the gear.

\section{Establishment of Rigid-flex Hybrid Model}

Romax Designer is a professional optimized software for design and analysis of gear transmission system, the microscopic analysis ability of Romax Designer is very powerful, computing capability on load distribution of the tooth is considered to be the most excellent. Therefore, the tooth profile can be optimized efficiently and reliably by using Romax powerful computing capability on load distribution of the tooth [7]. NGW31 planetary gear reducer is made up of the single-stage planetary gear transmission, its transmission structure diagram as is shown in Fig. 1.

Structure and Parameters of NGW31 Planetary Gear Reducer. The NGW31 planetary gear reducer which is studied in this paper is composed of the single stage planetary gear transmission, and its transmission structure diagram as shown in Fig. 1, among them the ring gear is fixed and sun gear rotates as input, so the ring gear will rotate as output[8]. Its input torque is $360 \mathrm{~N} \cdot \mathrm{m}$ and input speed is 640r/min. The design parameters of the gears as shown in Table 1.

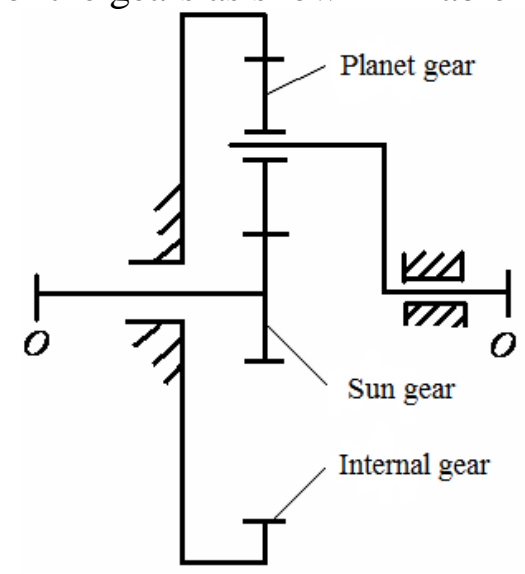

Figure 1. NGW31 planetary gear transmission structure diagram

This paper takes the micro geometric analysis module of Romax into use, and the sun gear and the planet gear are taken as the research objects [9-10]. The distribution of tooth surface contact stress of the sun gear and the planet gear before modification shape as shown in Fig. 2 and Fig. 3 respectively.

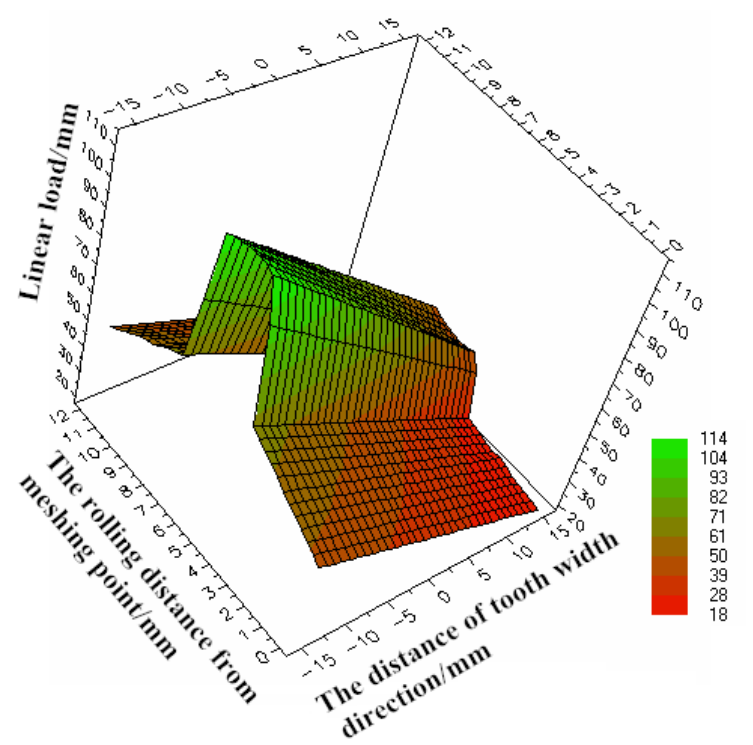

Figure 2. Tooth surface contact stress distribution of the sun gear before modification shape 


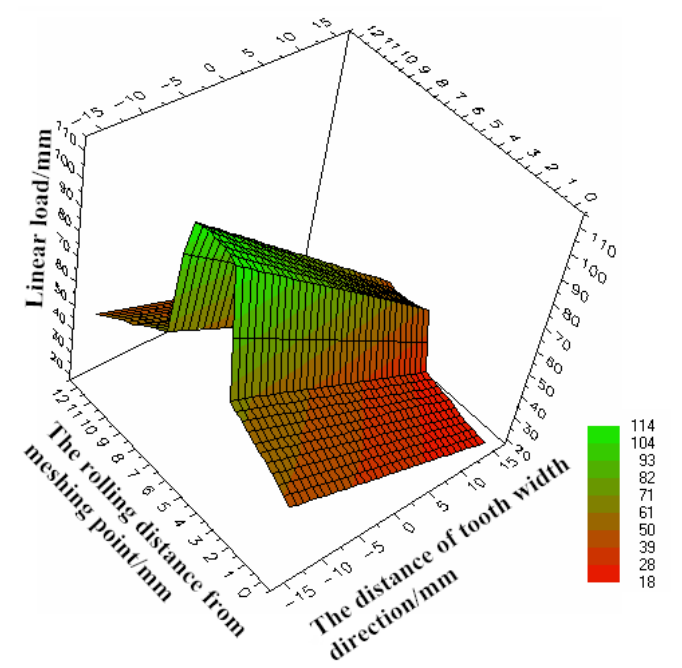

Figure 3. Tooth surface contact stress distribution of the planet gear before modification shape

It can be seen from Fig. 2 and Fig. 3, there is existing serious offset load along the tooth width direction, the maximum line contact load of tooth surface is up to $114 \mathrm{~N} / \mathrm{mm}$, which is located in the left side of the tooth width. It will affect the gear fatigue life seriously, so the gear needs to modify shape reasonably.

\section{Tooth Shape Optimization Based on Romax Designer}

The analysis of meshing dislocation of the sun gear and the planet gear is shown in Fig. 4. In Fig. 4, abscissa is the meshing tooth wide overlap and vertical coordinate is the displacement along the meshing line. The dislocation quantity of the sun gear and the planet gear is $4.57 \mathrm{~mm}$.

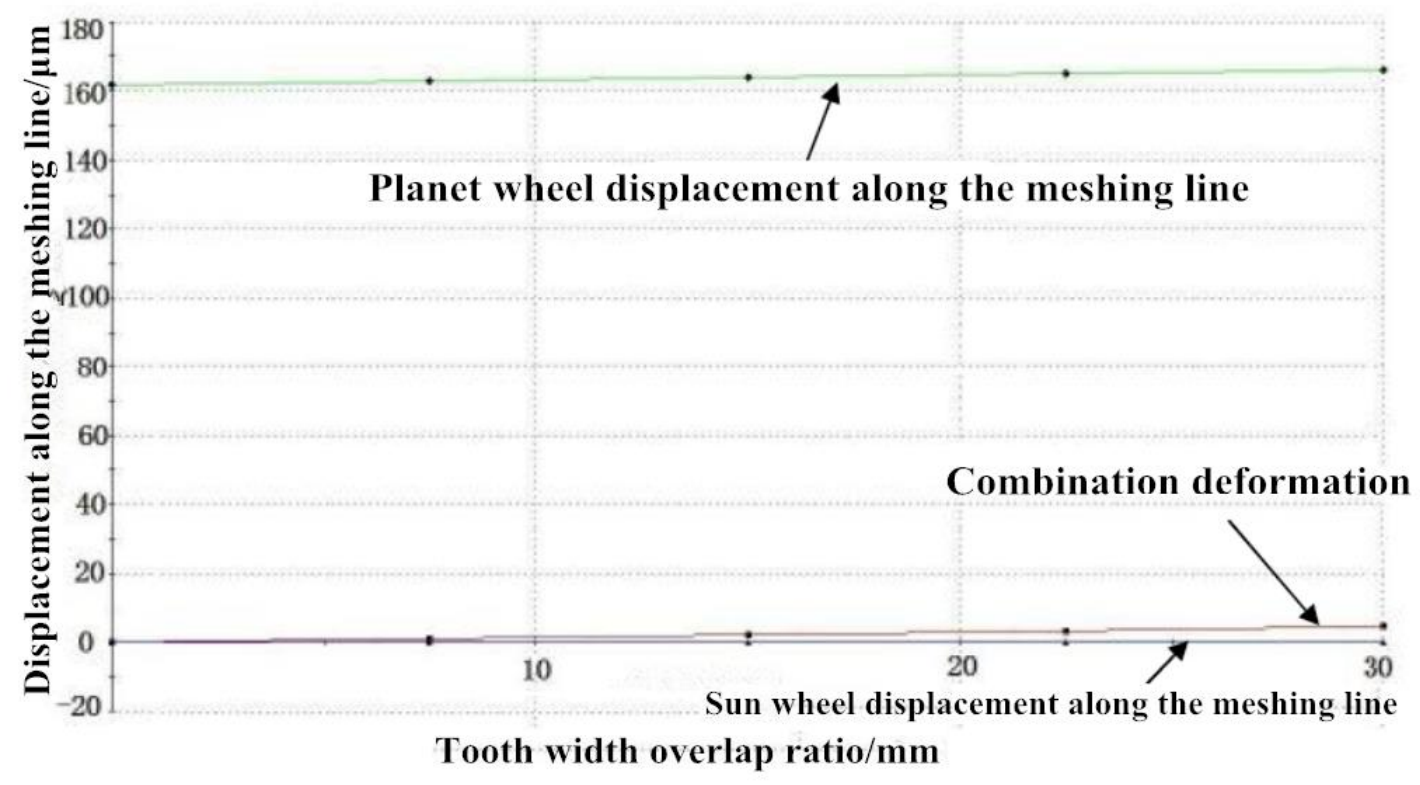

Figure 4. Meshing dislocation of the sun gear and planet gear

For tooth surface offset load, gear profile modification is adopted to improve the distribution of tooth surface contact stress, the specific method is to remove moderate material on the side that the unit load is larger in the tooth wide direction of gears. After completing the modification by Romax Designer, the distribution of tooth surface contact stress of the sun gear and the planet gear is shown in Fig. 5 and Fig. 6. 


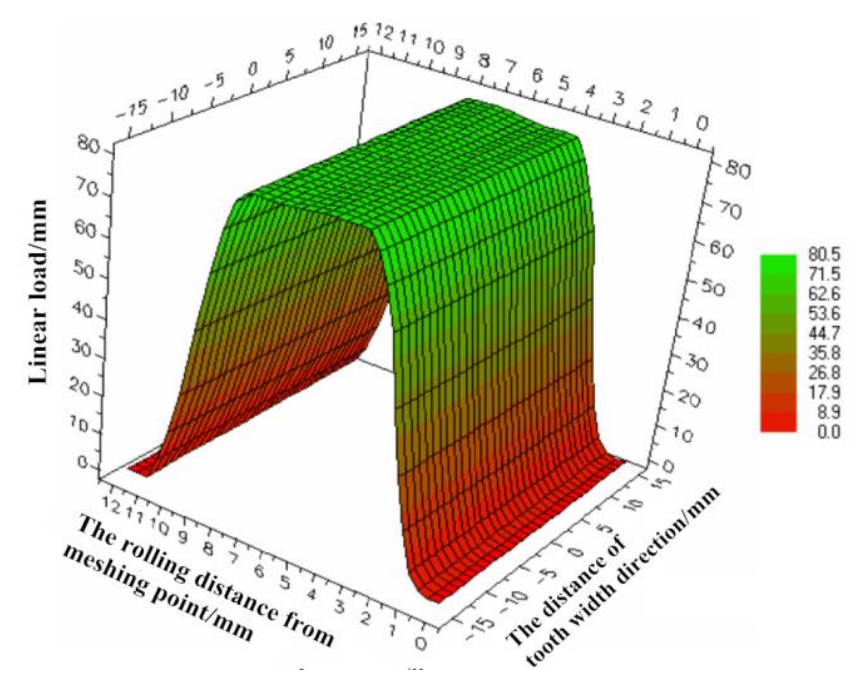

Figure 5. Tooth surface contact stress distribution of the sun gear after modification shape

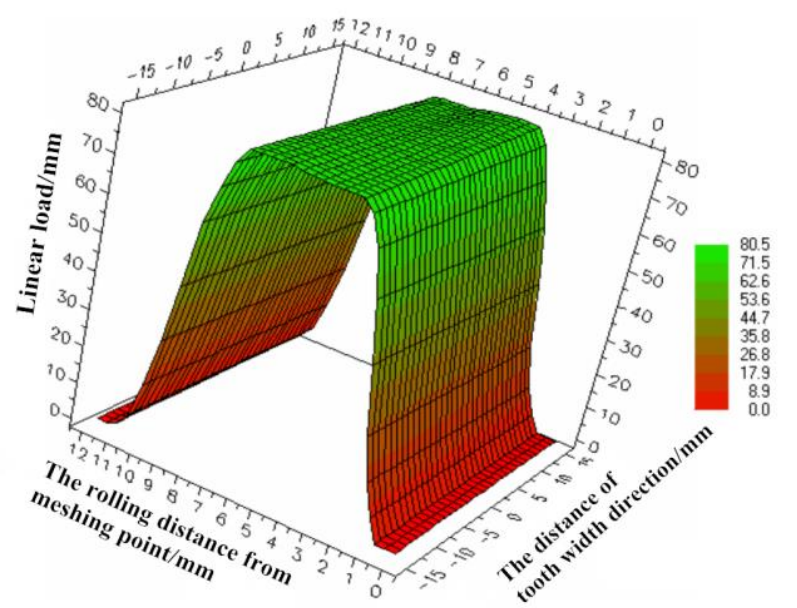

Figure 6. Tooth surface contact stress distribution of the planet gear after modification shape

It can be seen from Fig. 5 and Fig. 6 that the maximum load on the tooth surface of per unit length is $80.5 \mathrm{~N} / \mathrm{mm}$ after modification shape, before modification shape is $114 \mathrm{~N} / \mathrm{mm}$, the maximum load of tooth surface after modification shape has been lower $29.4 \%$ than before modification shape. At the same time, the load distribution of the whole tooth surface is more uniform after modification shape. The stress of the tooth profile is mainly concentrated in the middle part. The load of the addendum and tooth root is smaller. It can be seen that the bearing capacity of the teeth is significantly improved after modification shape. The shock is decreased when the gear come into meshing and exited the meshing. The stability of the transmission is improved

\section{Conclusion}

With the NGW31 planetary gear as a research object, it was modified and optimized by Romax Designer gear transmission simulation software. Comparing with the tooth surface contact stress distribution of the sun and planets wheel of NGW31 planetary gear to modify front and back, maximum load of tooth surface of per unit length is $80.5 \mathrm{~N} / \mathrm{mm}$ after modifying sun and planets wheel. It is $114 \mathrm{~N} / \mathrm{mm}$ before modifying sun and planets wheel, maximum load of tooth surface after modifying is lower $29.4 \%$ than before modifying. It suggests that the bearing capacity of the gear has been improved obviously after modifying. The shock is decreased when the gear come into meshing and exited the meshing, and stationary of transmission is improved, achieving gear tooth profile optimization. 


\section{References}

[1] Y. Tang, S. Chang and S.G. Luan, et al: Study on tooth surface modification in increasing gearbox for the wind-driven generator of planetary system. Machinery Design and Manufacture, (2011) No.9, p.93-95.

[2] X.C. Xu, A.P. Song and L.F. Zhang, et al: Research on gear comprehensive modification. Journal of Mechanical Transmission, Vol. 35 (2011) No.11, p.21-25, 29.

[3] Y. Yuan: The study of gear yawps and gear profiling. Mechanical Research and Application, Vol. 19 (2011) No.5, p.7-9.

[4] C. Wang, H. Liu and C.L. Xiang: Influences of profile modification on dynamic characteristics of involute spur gears under a fluctuating torque. Journal of Vibration and Shock, Vol. 33(2014) No.2, p.32-38.

[5] J.H. Xue, W. Li: Tooth profile modification mechanism and its influence on temperature fields. Journal of Northeastern University (Natural Science), Vol. 34(2013) No.12, p.1763-1767.

[6] C.G. Fang, X.D. Huang and E.K. Guo, et al: Tool path optimization for lead modification based on simultaneous contact line. Computer Integrated Manufacturing Systems, Vol. 20(2014) No.2, p.361-370.

[7] J.J. Yang, W. Liu and H. Zhang, et al: Research of the optimization design and experimental of gear modification based on ROMAX. Journal of Mechanical Transmission, Vol. 39(2015) No.10, p.158-161.

[8] F.M Ye, J Gao and W Jiang; Unequal assembly method and Pro/E modeling simulation of NGW planetary gear train. Journal of Jiangsu University of Science and Technology, Vol. 26(2012) No.6, p.254-257.

[9] F.Z. Sun: Analysis on gear modification of a tractor transmission based on Romax software. Journal of Shandong Agricultural University (Natural Science Edition), Vol. 45(2014) No.5, p.702-705

[10] X.L Zhu, H.G Xiong; Finite element modal analysis of reducer box based on Romax. Journal of Mechanical Transmission, Vol. 37(2013) No.2, p.94-96. 